\title{
Analysis on the level of IL-6, IL-21, AMH in patients with auto-immunity premature ovarian failure and study of correlation
}

\author{
SHULAN SUN ${ }^{1}$, HONG CHEN $^{1}$, XIAOXIA ZHENG ${ }^{1}$, CHUANYAN MA $^{2}$ and RUIQIN YUE ${ }^{3}$ \\ Departments of ${ }^{1}$ Gynaecology and ${ }^{2}$ Obstetrics, Binzhou City Center Hospital, Binzhou, Shandong 251700; \\ ${ }^{3}$ Department of Gynaecology, The Second People's Hospital of Liaocheng, Linqing, Shandong 252600, P.R. China
}

Received October 2, 2017; Accepted July 31, 2018

DOI: $10.3892 /$ etm.2018.6592

\begin{abstract}
Expression of interleukin-6 (IL-6), interleukin-21 (IL-21) and anti-müllerian hormone (AMH) in premature ovarian failure (POF) patients were observed to explore the correlation of each indicator and its significance in POF. One hundred and forty-two patients diagnosed with POF in Binzhou City Center Hospital from June 2014 to December 2015 were selected as the observation group. At the same time, another 140 healthy women were selected as the control group. The serum levels of IL-6, IL-21, AMH, follicle stimulating hormone (FSH) and luteinizing hormone ( $\mathrm{LH})$, estradiol (E2), testosterone (T) and basal antral follicle count (AFC), and mean ovarian volume (MOV) were determined and compared; correlation analysis of IL-6, IL-2l and AMH with other indicators was performed. Compared to the control group, the serum levels of IL-6, IL-21, FSH and LH in the observation group were significantly higher $(\mathrm{P}<0.05)$, while $\mathrm{E} 2, \mathrm{~T}, \mathrm{AMH}$ levels in the serum, AFC and MOV were significantly lower $(\mathrm{P}<0.05)$. Spearman's correlation analysis showed that IL-6, IL-21 was positively correlated with FSH and $\mathrm{LH}(\mathrm{P}<0.05)$, but negatively correlated with E2, T and MOV $(\mathrm{P}<0.05)$. AMH was negatively correlated with FSH and LH, but positively correlated with E2, T and MOV. Our results showed that the expression of IL-6, IL-21 and AMH were related to the occurrence and development of POF, IL-6, IL-21 and AMH can be used as the primary screening indexes for POF patients.
\end{abstract}

\section{Introduction}

Premature ovarian failure (POF) refers to amenorrhea in women before the age of 40 due to ovarian failure (1), it is a spontaneous, heterogeneous disease, main manifestations are amenorrhea, infertility and perimenopausal syndrome because

Correspondence to: Ms. Shulan Sun, Department of Gynaecology, Binzhou City Center Hospital, 108 Huancheng South Road, Huimin, Binzhou, Shandong 251700, P.R. China

E-mail: stjdhf@163.com

Key words: premature ovarian failure, IL-6, IL-21, anti-müllerian hormone of low estrogen (2). The etiology and pathogenesis of POF is not yet known, and it is believed that it is mainly related to the permanent damage of ovaries. Traumatic factors include trauma, radiotherapy and chemotherapy, immunity and inheritance (3). The study found that approximately $30 \%$ of POF are related to immune abnormalities (4), it can be induced that POF is a more common type clinically. American Society of Fertility divides the disease process into four stages: normal, latent, biochemical abnormalities and clinical abnormalities (5). Because of the latency and nature of the progress, patients are often in advanced stage when going for the treatment, making treatment more difficult. Early detection of POF is the key to diagnosis and treatment. In recent years, cytokines have become a hotspot for study. It is shown that interleukin-6 (IL-6) and interleukin-21 (IL-21) play important roles in immune diseases $(6,7)$, anti-müllerian hormone $(\mathrm{AMH})$ is a serological marker for assessing ovarian reserve function (8). However, IL-6, IL-21 and AMH in POF patients is rarely reported. This study was designed to provide a new target for the diagnosis and treatment of patients with POF by studying the levels of IL-6, IL-21 and AMH in patients with POF.

\section{Patients and methods}

Clinical data. One hundred and forty-two POF patients with complete clinical data admitted into Binzhou City Center Hospital (Binzhou, China) from June 2014 to December 2015 were selected as the observation group, all cases were in line with the diagnostic criteria of POF. The mean age of the observation group was $29.17 \pm 7.45$ years, the mean gravidity was $1.72 \pm 1.89$, the average parity was $1.12 \pm 1.58$ and the average body mass index (BMI) was $20.31 \pm 3.67 \mathrm{~kg} / \mathrm{m}^{2}$. One hundred and forty cases of healthy women with normal ovarian function in the hospital were collected as the control group, the age matching 1:1 ratio with the observation group. There was no significant difference in mean age, gravidity, parity and BMI between the two groups $(\mathrm{P}>0.05)$ (Table I). This study was approved by the Ethics Committee of Binzhou City Center Hospital, the patients were informed and signed the consent form.

Materials. IL-21 radioimmunoassay kit (RIA-141), LH radioimmunoassay kit (RIA-24), T radioimmunoassay kit (XFFM177D), E2 radioimmunoassay kit (XFFM182D) and FSH radioimmunoassay kit (RIA-23) was from Shanghai 
Table I. General condition of patients.

\begin{tabular}{lrrrr}
\hline $\begin{array}{l}\text { General } \\
\text { conditions }\end{array}$ & $\begin{array}{c}\text { Observation } \\
(\mathrm{n}=42)\end{array}$ & $\begin{array}{c}\text { Control } \\
(\mathrm{n}=40)\end{array}$ & $\mathrm{t} / \chi^{2}$ value & P-value \\
\hline Age (years) & $29.17 \pm 7.45$ & $29.21 \pm 6.78$ & 1.729 & 0.168 \\
Gravidity (time) & $1.72 \pm 1.89$ & $1.66 \pm 2.01$ & 1.834 & 0.152 \\
Parity (time) & $1.12 \pm 1.58$ & $1.20 \pm 1.46$ & 1.912 & 0.089 \\
BMI $\left(\mathrm{kg} / \mathrm{m}^{2}\right)$ & $20.31 \pm 3.67$ & $20.24 \pm 3.93$ & 1.645 & 0.186 \\
\hline
\end{tabular}

Table II. Comparison of serum levels of sex hormones in the groups.

\begin{tabular}{lcccr}
\hline $\begin{array}{l}\text { Sex } \\
\text { hormones }\end{array}$ & $\begin{array}{c}\text { Observation } \\
(\mathrm{n}=42)\end{array}$ & $\begin{array}{c}\text { Control } \\
(\mathrm{n}=40)\end{array}$ & $\mathrm{t} / \chi^{2}$ value & P-value \\
\hline FSH (IU/l) & $83.38 \pm 27.54$ & $5.12 \pm 0.78$ & 51.273 & 0.009 \\
LH (IU/l) & $43.27 \pm 21.62$ & $4.36 \pm 1.01$ & 79.348 & 0.001 \\
E2 (pg/ml) & $16.13 \pm 7.17$ & $42.94 \pm 13.76$ & 65.647 & 0.004 \\
T (ng/dl) & $31.24 \pm 8.79$ & $43.65 \pm 11.89$ & 28.745 & 0.023 \\
AFC & $1.25 \pm 0.34$ & $7.17 \pm 0.67$ & 83.126 & $<0.001$ \\
\hline
\end{tabular}

Xinfan Biotechnology Co., Ltd. (Shanghai, China). IL-2 ELISA kit (XFE1457A), IL-6 ELISA kit (XFE1011A) was from Shanghai Xinfan Biotechnology Co., Ltd. AMH ELISA kit (mEA-H12007) was from Shanghai Ximin Biotechnology Co. Ltd.

\section{Diagnostic, inclusion and exclusion criteria}

Diagnostic criteria (2). i) Age $<40$ years, amenorrhea $\geq 6$ months or $\geq 3$ cycles, with or without perimenopausal syndrome symptoms (hot flashes, palpitation and insomnia). ii) Interval of more than 1 month, serum follicle stimulating hormone $(\mathrm{FSH}) \geq 40$ IU/l two times and above. The above two points had to be met at the same time.

Inclusion criteria. i) Meet the POF diagnostic criteria as stated above. ii) Accompanied by Hashimoto thyroiditis, rheumatoid arthritis (RA), ulcerative colitis (Crohn's), systemic lupus erythematosus (SLE) and other immune abnormalities. iii) B-ultrasound confirmed no diameter $>10 \mathrm{~mm}$ follicles in the ovary, endometrium $<4 \mathrm{~mm}$.

Exclusion criteria. i) Malignant tumors; ii) severe infection; iii) severe liver and kidney dysfunction; iv) uterus or ovary has been removed.

Methods. General records, including age, menstrual history, marriage history, complications (especially immune diseases). The weight of all patients was measured after fasting and wearing light clothes, and then the height of the patient was measured. $\mathrm{BMI}=$ weight $/$ height $^{2}$.

Detection of serum markers. The morning fasting elbow vein blood on the 5th day of menstrual cycle was obtained from all patients, the samples were centrifuged with anticoagulant,
Table III. Serum levels of IL-6, IL-21, AMH and MOV.

\begin{tabular}{lccrr}
\hline Index & $\begin{array}{c}\text { Observation } \\
(\mathrm{n}=42)\end{array}$ & $\begin{array}{c}\text { Control } \\
(\mathrm{n}=40)\end{array}$ & $\mathrm{t} / \chi^{2}$ value & P-value \\
\hline IL-6 $(\mathrm{pg} / \mathrm{ml})$ & $16.28 \pm 4.31$ & $1.61 \pm 0.75$ & 92.125 & $<0.001$ \\
IL-21 $(\mathrm{pg} / \mathrm{ml})$ & $163.24 \pm 38.72$ & $117.12 \pm 17.63$ & 34.191 & 0.013 \\
AMH $(\mathrm{ng} / \mathrm{ml})$ & $2.51 \pm 1.40$ & $4.92 \pm 0.42$ & 49.307 & 0.008 \\
MOV $\left(\mathrm{cm}^{3}\right)$ & $2.06 \pm 0.59$ & $7.35 \pm 1.29$ & 63.104 & $<0.001$ \\
\hline
\end{tabular}

at $2,500 \mathrm{x} \mathrm{g}$ at $4^{\circ} \mathrm{C}$ for $5 \mathrm{~min}, 3 \mathrm{ml}$ of supernatant serum was obtained, stored at $-20^{\circ} \mathrm{C}$ in an incubator for further testing. All operations were in strict accordance with the corresponding instructions (Shanghai Enzyme-linked Biotechnology Co., Ltd., Shanghai, China).

Radioimmunoassay. Serum levels of IL-21, FSH, LH (luteinizing hormone), E2 (estradiol) and T (testosterone) were measured by radioimmunoassay (a method of competitive inhibition with antibodies by using isotopic and unlabeled antigens).

ELISA serum. AMH levels were measured by enzyme-linked immunosorbent assay, serum IL-6 levels were measured by double-antibody sandwich ELISA. The main steps were as follows: Antibody-coating $\rightarrow$ Add antigen to be detected $\rightarrow$ Add enzyme labelled antibody $\rightarrow$ Add substrate liquid $\rightarrow$ Add terminal liquid $\rightarrow$ Result analysis $\rightarrow$ The concentration of IL-2 and IL-6 in serum was calculated by drawing a standard curve (the antibodies were included in the ELISA kit).

All patients underwent transvaginal ultrasonography to check the antral follicle counts (AFC) and bilateral ovarian volume, excluding the measurement error, measurements of each index were repeated three times, and the mean ovarian volume (MOV) was calculated.

Statistical methods. SPSS18.0 (SPSS Inc., Chicago, IL, USA) software was used for analysis. Mean \pm standard deviation was used for normal measurement data analysis, t-test was selected for comparison between groups, $\chi^{2}$ test was used for comparison of enumeration data between groups. Spearman's correlation analysis was performed. $\mathrm{P}<0.05$ was considered to indicate a statistically significant difference.

\section{Results}

Comparison of serum levels of sex hormones and AFC. For patients in the observation group, the mean serum FSH was $83.38 \pm 27.54 \mathrm{IU} / \mathrm{l}$, LH was $43.27 \pm 21.62 \mathrm{IU} / 1$, E2 was $16.13 \pm 7.17 \mathrm{pg} / \mathrm{ml}$, T was $31.24 \pm 8.79 \mathrm{ng} / \mathrm{dl}$, AFC was $1.25 \pm 0.34$, and for the control group, FSH was 5.12 $\pm 0.78 \mathrm{IU} / 1$, LH was $4.36 \pm 1.01 \mathrm{IU} / 1$, E2 was $42.94 \pm 13.76 \mathrm{pg} / \mathrm{ml}$, T was $43.65 \pm 11.89 \mathrm{ng} / \mathrm{dl}, \mathrm{AFC}$ was $7.17 \pm 0.67$, the serum levels of FSH and LH of the observation group was significantly higher than that of the control group $(\mathrm{P}<0.05)$, while the level of $\mathrm{E} 2, \mathrm{~T}$ and AFC of the observation group was significantly lower than that of the control group $(\mathrm{P}<0.05)$ (Table II). 
Table IV. Correlation between IL-6 and IL-21 and AMH, FSH and LH.

\begin{tabular}{lrrrrr}
\hline & \multicolumn{2}{c}{ FSH } & & \multicolumn{2}{c}{ LH } \\
\cline { 2 - 3 } \cline { 6 - 6 } Index & \multicolumn{1}{c}{$r$} & P-value & & $r$ & P-value \\
\hline IL-6 & 0.669 & $<0.05$ & & 0.675 & $<0.05$ \\
IL-21 & 0.671 & $<0.05$ & & 0.820 & $<0.05$ \\
AMH & -0.523 & $<0.05$ & & -0.321 & $<0.05$ \\
\hline
\end{tabular}

Table V. Correlation between IL-6 and IL-21 and AMH, E2, $\mathrm{T}$ and MOV.

\begin{tabular}{|c|c|c|c|c|c|c|}
\hline \multirow[b]{2}{*}{ Index } & \multicolumn{2}{|c|}{ E2 } & \multicolumn{2}{|c|}{$\mathrm{T}$} & \multicolumn{2}{|c|}{ MOV } \\
\hline & $\mathrm{r}$ & P-value & $\mathrm{r}$ & P-value & $\mathrm{r}$ & P-value \\
\hline IL-6 & -0.631 & $<0.05$ & -0.452 & $<0.05$ & -0.673 & $<0.05$ \\
\hline IL-21 & -0.642 & $<0.05$ & -0.460 & $<0.05$ & -0.681 & $<0.05$ \\
\hline AMH & 0.331 & $<0.05$ & 0.507 & $<0.05$ & 0.468 & $<0.05$ \\
\hline
\end{tabular}

Serum levels of serum cytokines and MOV between the two groups. The level of serum IL-6 in the observation group was $16.28 \pm 4.31 \mathrm{pg} / \mathrm{ml}$, IL-21 level was $163.24 \pm 38.72 \mathrm{pg} / \mathrm{ml}$, AMH was $2.51 \pm 1.40 \mathrm{ng} / \mathrm{ml}$, MOV was $2.06 \pm 0.59 \mathrm{~cm}^{3}$, while the serum IL-6 level was $1.61 \pm 0.75 \mathrm{pg} / \mathrm{ml}$, IL-21 level was $117.12 \pm 17.63 \mathrm{pg} / \mathrm{ml}$, AMH was $4.92 \pm 0.42 \mathrm{ng} / \mathrm{ml}$, MOV was $7.35 \pm 1.29 \mathrm{~cm}^{3}$. Compared with the control group, the serum levels of IL-6 and IL-21 were significantly increased in the observation group $(\mathrm{P}>0.05)$, while the serum levels of AMH and MOV were significantly decreased $(\mathrm{P}<0.05)$ (Table III).

The correlation between serum indexes and MOV. IL-6 was positively correlated with FSH and LH according to Spearman's correlation analysis $(\mathrm{r}=0.669,0.675, \mathrm{P}<0.05), \mathrm{IL}-21$ was positively correlated with FSH and LH $(r=0.671,0.820, \mathrm{P}<0.05)$, AMH was negatively correlated with FSH and LH $(r=-0.523$, $-0.321, \mathrm{P}<0.05$ ) (Table IV). IL-6 was negatively correlated with E2, $\mathrm{T}$ and MOV ( $r=-0.631,-0.452,-0.673, \mathrm{P}<0.05)$, IL-21 was negatively correlated with E2, T and MOV $(r=-0.642,-0.460$, $-0.681, \mathrm{P}<0.05), \mathrm{AMH}$ was positively correlated with $\mathrm{E} 2, \mathrm{~T}$ and MOV $(r=0.331,0.507,0.468, \mathrm{P}<0.05)($ Table V).

\section{Discussion}

The etiology of POF is not clear as yet, although not lethal, POF has brought catastrophic injury to patients. The difficulty of treatment is a major challenge for in clinic. If the early stage of the disease can be identified timely, it will help improve the patient's reproductive outcome. Studies have found that $\mathrm{CD}^{+} \mathrm{T}$ lymphocyte subsets and ovarian antigens change the concentration of anti-ovarian antibody, immune cells and cytokines by stimulating the body's immune system, which is considered to have an important link with the occurrence of POF (9). In addition, it has been found that the number of
$\mathrm{CD}^{+} \mathrm{T}$ lymphocytes is increased in the peripheral blood of primary POF patients. Compared with the control group, the CD8 density on the T cells of the observation group is significantly increased, suggesting that POF is caused by immune abnormalities (10).

IL-6 is a glycopeptide with a molecular weight of $26 \mathrm{kD}$ and its gene is located on chromosome 7 (11). IL-6 is mainly secreted by antigen-presenting cells (macrophages, dendritic cells), B cells, T cells, non-hematopoietic cells, osteoblasts and mesangial cells (12). IL-6 is connected with soluble IL-6 connexin (IL-6R) and cell membrane receptor complex composed of glycoprotein gp130. The complex of IL-6 and IL-6R plays a role in multiple processes of immune response and can play an immunomodulatory role by promoting B cell proliferation and promoting $\mathrm{T}$ cell proliferation and secretion of antibodies (13), it also plays an important role in hematopoietic effect, interfering with metabolism, and immune diseases (6). De Benedetti found that (14), compared with after hormone replacement therapy + immunotherapy and the control group, the serum IL-6 level of POF patients before therapy was significantly higher. In this study, serum IL-6 concentration in immune POF group was significantly higher than the normal control group $(\mathrm{P}<0.05)$, indicating that immune ovarian premature failure and IL- 6 expression are correlated.

IL-21 is a member of the IL-2 cytokine family and IL-21 binds to its receptor IL-21R to produce biological effects (15). Studies have found that IL-21 has an important link with some immune diseases (RA, Crohn's and SLE), and is related with the severity of the disease and the degree of relief (16). This study found that serum IL-21 levels in patients with POF were significantly higher than those in the control group $(\mathrm{P}<0.05)$, indicating that IL-21 may be associated with the immune mechanism of POF. Coulam et al found that (17), pathologic biopsy of part of the ovarian tissue of POF patients showed follicular, especially mature follicular inflammatory cell infiltration (lymphocytes, plasma cells). The elevated levels of IL-21 in serum of patients with POF may be mediated by the corresponding receptors on various inflammatory cells on the ovarian surface, activating their downstream signaling pathways [MAPK (18), PI3K/AKt and JAK1/JAK3 (19)], regulating the body immune network, the mechanism needs further study.

AMH belongs to the transforming growth factor beta superfamily, which is not expressed in female embryos, and is mainly secreted by granulosa cells (preantral follicles and sinus follicles) after birth, and does not fluctuate with the menstrual cycle $(20,21)$. Serum AMH has been regarded as a serological marker for predicting ovarian reserve function, and is widely used in the clinical practice of assisted reproduction. The serum level of AMH is positively correlated with the number of oocytes retrieved and ovarian response (8). In this study, we showed that AMH levels in POF patients were significantly lower than those in normal controls $(\mathrm{P}<0.05)$, indicating that $\mathrm{AMH}$ levels were associated with ovarian function. Méduri et al (22) found that the decrease in serum AMH levels in POF patients may be associated with defects in granulocytes in sinus follicles, and that defected granulocytes secrete significantly lower AMH than healthy people.

At present, there is no single marker that can predict ovarian reserve function perfectly, and joint testing is expected 
to improve the accuracy. In this study, it was observed that IL-6 and IL-21 were negatively correlated with AMH $(\mathrm{P}<0.05)$ by analyzing the correlation between serum IL-6, IL-2l and AMH levels in patients with POF, which indicated that the higher the level of IL-6 and IL-21, the lower the AMH level, the worse the ovarian reserve function. In clinical practice, it is suggested to improve the prediction for ovarian reserve function by monitoring the levels of AMH, IL-6 and IL-21, in order to provide early diagnosis and intervention, therefore improving the quality of life and the reproductive outcomes of patients as much as possible.

Surgery will cause different degrees of damage to premature ovarian failure patients and it is not repeatable and may aggravate ovarian damage. Whereas, serum samples are easy to operate, so this study used the patient serum for analysis. We will try to use animal-based model for work in the following study. At the same time, the number included in this study is relatively small, we should increase the number of samples in a multi-center and more in-depth way, which may improve the results.

\section{Acknowledgements}

Not applicable.

\section{Funding}

No funding was received.

\section{Availability of data and materials}

The datasets used and/or analyzed during the present study are available from the corresponding author on reasonable request.

\section{Authors' contributions}

SS drafted this manuscript. XZ, CM and HC were mainly devoted on collecting and interpreting the data. XZ and $\mathrm{CM}$ revised it critically for important intellectual content. SS and RY were responsible for the conception and design of the study. All authors read and approved the final manuscript.

\section{Ethics approval and consent to participate}

The study was approved by the Ethics Committee of Binzhou City Center Hospital (Binzhou, China). Signed informed consents were obtained from the patients or the guardians.

\section{Patient consent for publication}

Not applicable.

\section{Competing interests}

The authors declare that they have no competing interests.

\section{References}

1. Beke A, Piko H, Haltrich I, Csomor J, Matolcsy A, Fekete G, Rigo J and Karcagi V: Molecular cytogenetic analysis of Xq critical regions in premature ovarian failure. Mol Cytogenet 6: $62,2013$.
2. Goswami D and Conway GS: Premature ovarian failure. Horm Res 68: 196-202, 2007.

3. Ghassemzadeh A, Farzadi L and Beyhaghi E: Premature ovarian failure risk factors in an Iranian population. Int J Gen Med 5: 335-338, 2012.

4. Conway GS, Kaltsas G, Patel A, Davies MC and Jacobs HS: Characterization of idiopathic premature ovarian failure. Fertil Steril 65: 337-341, 1996.

5. Wittenberger MD, Hagerman RJ, Sherman SL, McConkieRosell A, Welt CK, Rebar RW, Corrigan EC, Simpson JL and Nelson LM: The FMR1 premutation and reproduction. Fertil Steril 87: 456-465, 2007.

6. Zhuang YB: IL-2, IL-6 expression in autoimmune premature ovarian failure and its clinical significance. Chin J Contemp Med 15: 46-47, 2015.

7. Sawalha AH, Kaufman KM, Kelly JA, Adler AJ, Aberle T, Kilpatrick J, Wakeland EK, Li QZ, Wandstrat AE, Karp DR, et al: Genetic association of interleukin-21 polymorphisms with systemic lupus erythematosus. Ann Rheum Dis 67: 458-461, 2008.

8. Knauff EA, Eijkemans MJ, Lambalk CB, ten Kate-Booij MJ, Hoek A, Beerendonk CC, Laven JS, Goverde AJ, Broekmans FJ, Themmen AP, et al; Dutch Premature Ovarian Failure Consortium: Anti-Mullerian hormone, inhibin B, and antral follicle count in young women with ovarian failure. J Clin Endocrinol Metab 94: 786-792, 2009.

9. Vital Reyes VS, Téllez Velasco S, Hinojosa Cruz JC, Ortiz Romero Mde J, Chavarría Olarte ME and Reyes Fuentes A: Serum levels of IL-1beta, IL-6 and TNF-alpha in infertile patients with ovarian dysfunction. Ginecol Obstet Mex 73: 604-610, 2005 (In Spanish).

10. Chernyshov VP, Radysh TV, Gura IV, Tatarchuk TP and Khominskaya ZB: Immune disorders in women with premature ovarian failure in initial period. Am J Reprod Immunol 46: 220-225, 2001.

11. Dayer JM and Choy E: Therapeutic targets in rheumatoid arthritis: The interleukin-6 receptor. Rheumatology (Oxford) 49: 15-24, 2010.

12. Dienz O, Eaton SM, Bond JP, Neveu W, Moquin D, Noubade R, Briso EM, Charland C, Leonard WJ, Ciliberto G, et al: The induction of antibody production by IL-6 is indirectly mediated by IL-21 produced by CD4 ${ }^{+}$T cells. J Exp Med 206: 69-78, 2009.

13. Youinou P and Jamin C: The weight of interleukin-6 in B cellrelated autoimmune disorders. J Autoimmun 32: 206-210, 2009.

14. De Benedetti F: Targeting interleukin-6 in pediatric rheumatic diseases. Curr Opin Rheumatol 21: 533-537, 2009.

15. Spolski R and Leonard WJ: Interleukin-21: Basic biology and implications for cancer and autoimmunity. Annu Rev Immunol 26: 57-79, 2008

16. Niu X, He D, Zhang X, Yue T, Li N, Zhang JZ, Dong C and Chen G: IL-21 regulates Th17 cells in rheumatoid arthritis. Hum Immunol 71: 334-341, 2010.

17. Coulam CB, Kempers RD and Randall RV: Premature ovarian failure: Evidence for the autoimmune mechanism. Fertil Steril 36: 238-240, 1981.

18. Zeng R, Spolski R, Casas E, Zhu W, Levy DE and Leonard WJ: The molecular basis of IL-21-mediated proliferation. Blood 109: 4135-4142, 2007

19. Nurieva R, Yang XO, Martinez G, Zhang Y, Panopoulos AD, Ma L, Schluns K, Tian Q, Watowich SS, Jetten AM, et al: Essential autocrine regulation by IL-21 in the generation of inflammatory T cells. Nature 448: 480-483, 2007.

20. La Marca A, Stabile G, Artenisio AC and Volpe A: Serum antiMullerian hormone throughout the human menstrual cycle. Hum Reprod 21: 3103-3107, 2006.

21. Li HW, Lee VC, Lau EY, Yeung WS, Ho PC and Ng EH: Role of baseline antral follicle count and anti-Mullerian hormone in prediction of cumulative live birth in the first in vitro fertilisation cycle: A retrospective cohort analysis. PLoS One 8: e61095, 2013.

22. Méduri G, Massin N, Guibourdenche J, Bachelot A, Fiori O, Kuttenn F, Misrahi M and Touraine P: Serum anti-Müllerian hormone expression in women with premature ovarian failure. Hum Reprod 22: 117-123, 2007. International (CC BY-NC-ND 4.0) License. 